\section{CD28.0X40 co-stimulatory combination is associated with long in vivo persistence and high activity of CAR.CD30 T cells}

\author{
Marika Guercio, ${ }^{1}$ Domenico Orlando, ${ }^{1}$ Stefano Di Cecca, ${ }^{1}$ Matilde Sinibaldi, ${ }^{1}$ \\ Iolanda Boffa, ${ }^{1}$ Simona Caruso, ${ }^{1}$ Zeinab Abbaszadeh, ${ }^{1}$ Antonio Camera, ${ }^{1}$ \\ Biancamaria Cembrola, ${ }^{1}$ Katia Bovetti, ${ }^{1}$ Simona Manni, ${ }^{1}$ Ignazio Caruana, ${ }^{1}$ \\ Roselia Ciccone, ${ }^{1}$ Francesca Del Bufalo, ${ }^{1}$ Pietro Merli, ${ }^{1}$ Luciana Vinti, ${ }^{1}$ Katia \\ Girardi, ${ }^{1}$ Annalisa Ruggeri, ${ }^{1}$ Cristiano De Stefanis, ${ }^{1}$ Marco Pezzullo, ${ }^{1}$ Ezio \\ Giorda, ${ }^{1}$ Marco Scarsella, ${ }^{1}$ Rita De Vito, ${ }^{2}$ Sabina Barresi, ${ }^{3}$ Andrea Ciolfi, ${ }^{3}$ Marco \\ Tartaglia, ${ }^{3}$ Lorenzo Moretta, ${ }^{4}$ Franco Locatelli, ${ }^{1,5 \#}$ Concetta Quintarelli ${ }^{1,6 \#}$ and \\ Biagio De Angelis ${ }^{1 \#}$
}

${ }^{1}$ Department of Onco-Hematology and Cell and Gene Therapy, Bambino Gesù Children's Hospital, IRCCS, Rome; ' ${ }^{2}$ epartment of Laboratories, Pathology Unit, Bambino Gesù Children's Hospital, IRCCS, Rome; ${ }^{3}$ Genetics and Rare Diseases Research Division, Ospedale Pediatrico Bambino Gesù IRCSS, Rome; ${ }^{4}$ Department of Immunology, Bambino Gesù Children's Hospital, IRCCS, Rome; ${ }^{5}$ Department of Pediatrics, Sapienza, University of Rome, Rome and ${ }^{6}$ Department of Clinical Medicine and Surgery, Federico II University, Naples, Italy

${ }^{\#} F L, C Q$ and BDA contributed equally as co-senior authors.

\section{ABSTRACT}

$\mathrm{T}$ he prognosis of many patients with chemotherapy-refractory or multiply relapsed $\mathrm{CD} 0^{+}$non-Hodgkin lymphoma (NHL) or Hodgkin lymphoma (HL) still remains poor, and novel therapeutic approaches are warranted to address this unmet clinical need. In light of this consideration, we designed and pre-clinically validated a chimeric antigen receptor (CAR) construct characterized by a novel anti-CD30 single-chain variable-fragment cassette, linked to $\mathrm{CD} 3 \zeta$ by the signaling domains of two co-stimulatory molecules, namely CD28.4-1BB or CD28.OX40. We found that CAR.CD30 T cells exhibit remarkable cytolytic activity in vitro against both HL and NHL cell lines, with sustained proliferation and pro-inflammatory cytokine production, even after multiple and sequential lymphoma-cell challenges. CAR.CD30 T cells also demonstrated anti-lymphoma activity in two in vivo xenograft immune-deficient mouse models of metastatic HL and NHL. We observed that administration of CAR.CD30 T cells, incorporating the CD28.OX40 co-stimulatory domains and manufactured in the presence of interleukin 7 and interleukin 15, were associated with the best overall survival in the treated mice, along with establishment of a long-term immunological memory able to protect mice from further tumor re-challenge. Our data indicate that, in the context of in vivo systemic metastatic xenograft mouse models, the co-stimulatory machinery of CD28.OX40 is crucial for improving persistence, in vivo expansion and proliferation of CAR.CD30 T cells upon tumor encounter. The CD28.OX40 co-stimulatory combination is ultimately responsible for the anti-tumor efficacy of the approach, paving the way to translate this therapeutic strategy into clinical use for patients with CD30+ $\mathrm{HL}$ and NHL.

\section{Introduction}

Use of chimeric antigen receptor (CAR) T cells is a new promising approach of adoptive cancer cell immunotherapy, combining antigen recognition by a monoclonal antibody with the effector function of $\mathrm{T}$ cells. ${ }^{1} \mathrm{CAR} \mathrm{T}$ cells directed against CD19 have been shown to induce sustained complete responses in patients with relapsed/refractory B-cell non-Hodgkin (NHL) lymphomas, particularly diffuse
Haematologica 2021

Volume 106(4):987-999

\section{Correspondence:}

BIAGIO DE ANGELIS

biagio.deangelis@opbg.net

FRANCO LOCATELLI

franco.locatelli@opbg.net

Received: July 8, 2019.

Accepted: March 24, 2020.

Pre-published: May 7, 2020

https://doi.org/10.3324/haematol.2019.231183

(C)2021 Ferrata Storti Foundation

Material published in Haematologica is covered by copyright. All rights are reserved to the Ferrata Storti Foundation. Use of published material is allowed under the following terms and conditions:

https://creativecommons.org/licenses/by-nc/4.0/legalcode. Copies of published material are allowed for personal or internal use. Sharing published material for non-commercial purposes is subject to the following conditions:

https://creativecommons. org//icenses/by-nc/4.0/legalcode sect. 3. Reproducing and sharing published material for commercial purposes is not allowed without permission in writing from the publisher. 
large B-cell lymphoma., ${ }^{2,3}$ However, alternative targets are needed for other types of lymphoma lacking CD19 expression, including diseases such as classical Hodgkin lymphoma (HL), anaplastic large-cell lymphoma and other T-cell lymphomas.

Although most patients with HL or NHL are cured with first-line therapies, a relevant proportion of them have primary refractory disease or experience relapse after initial response to treatment. ${ }^{4}$ The standard of care for patients who relapse after first-line treatment is intensive chemotherapy followed, in responders, by autologous stem cell transplantation. Although autologous transplantation offers the potential to cure about half of patients, the prognosis of subjects relapsing after the autograft or not eligible for transplantation is poor. ${ }^{5}$ Novel therapies are, therefore, desirable for patients with relapsed/refractory lymphoma.

Despite biological differences, HL and NHL have proven to be good targets for immunotherapy: indeed, both occur in the immune-rich lymphoid tissues and are easily accessible to antibody- and cell-based immunotherapy. ${ }^{5}$ Moreover, CD30, a cell-membrane protein belonging to the tumor-necrosis-factor receptor superfamily 8 , can be found on the cell-surface of both HL and selected NHL including anaplastic large-cell lymphoma, diffuse large B-cell lymphoma, primary mediastinal B-cell lymphoma, ${ }^{6}$ peripheral T-cell lymphoma, ${ }^{7}$ and adult T-cell leukemia/lymphoma, ${ }^{8}$ as well as in rare solid tumors, ${ }^{9}$ including embryonal carcinomas ${ }^{10}$ and seminomas. ${ }^{11}$ Its restricted expression on a subset of normal, activated $T$ and $\mathrm{B}$ cells $^{12,13}$ renders CD30 an excellent candidate for immune-based therapies, with a low risk of off-tumor, on-target toxicity.

CD30 has been extensively explored as a target for antibody-based therapy. The most remarkable results have been achieved with brentuximab-vedotin, an antibodydrug conjugate directed against CD30, shown to be well tolerated and associated with relevant activity in HL and anaplastic large-cell lymphoma. ${ }^{14}$ Although brentuximabvedotin appears to induce excellent responses. ${ }^{15,16}$ this antibody-drug conjugate is also associated with adverse events leading to treatment discontinuation in a significant proportion of patients. ${ }^{17}$ To overcome the challenges presented by antibody-based therapy, namely limited response durability and reduced tumor penetration. ${ }^{18}$ CAR T cells have been explored.

Immunotherapeutic approaches with CAR targeting CD30 have shown efficacy in preclinical models, ${ }^{19,20}$ and these results have been translated into the clinic in two trials based on second-generation CD30.CAR T cells, including either CD28 or 4-1BB co-stimulatory domains. ${ }^{21,22}$ The clinical efficacy of these second-generation CD30.CAR T cells was, however, suboptimal, as inconsistent responses were observed, most patients having either stable disease after multiple CAR T-cell infusions, or no response at all. Overall, lymph nodes showed better responses than extranodal lesions and CAR T cells did not persist longer than 60 days after infusion. Notably, two studies with CD30.CAR T cells supported several other clinical observations in different settings, ${ }^{23,24}$ showing a correlation between CAR T-cell persistence and patients' outcome. We therefore sought to optimize the CAR.CD30 T-cell approach by using a novel singlechain variable fragment (scFv), as well as a novel thirdgeneration construct.
We demonstrate that, with our CAR.CD30 T-cell approach, the use of the novel scFv, the combination of the co-stimulatory molecules CD28 and OX40, as well as a production process based on the addition of interleukin 7 (IL7) and interleukin 15 (IL15), are all relevant to drive high in vivo proliferation/expansion, long-term persistence and establishment of the immunological memory necessary to control lymphoma recurrence.

\section{Methods}

\section{Generation of retroviral vectors and transduction method of T cells}

The scFv for CAR.CD30 molecules is derived from the AC10 monoclonal antibody. ${ }^{25}$ The details of the constructs are provided in Figure 1A, Online Supplementary Figure S1A, Online Supplementary Materials and Online Supplementary Table S1, which report the amino-acid sequences for all the construct components. Retroviral supernatant was generated in 293T-cells $s^{19,26,27}$ and quantified using a Retro- $X^{\mathrm{M}}$ qRT-PCR Titration Kit (Takara) to be used at $10^{9}$ retrovirus-copies $/ 0.5 \times 10^{6} \mathrm{~T}$ cells. The supernatant was used to transduce primary $\mathrm{T}$ cells derived from peripheral blood mononuclear cells of healthy donors (Ethical Committee approval n. 969/2015 protocol n. 669LB). More details on transduction are provided in the Online Supplementary Materials.

\section{Phenotypic analysis}

The following monoclonal antibodies were used: CD3, CD4, CD8, CD45RA, CD45RO, CD62L, CD223, CD274, CD279, and TIM3 (BD Pharmigen, USA). The expression of CAR.CD30 on $T$ cells was evaluated using anti-CD34 antibody (R\&D, USA) or the Pierce Recombinant Biotinylated Protein L. ${ }^{28}$ (Thermo Fisher Scientific, USA). The gating strategy is reported in Online Supplementary Figure S2.

\section{In vitro anti-lymphoma activity}

CAR T-cell cytotoxicity was evaluated using a ${ }^{51} \mathrm{Cr}$-release assay. ${ }^{20}$ For co-culture experiments, $\mathrm{T}$ cells and lymphoma-cell lines (Ethical Committee approval n. 652/2018 protocol n. GR2016-02364546), were plated for 7 days, and residual tumor analyzed by fluorescent activated cell sorting (FACS). For "stressed" co-cultures, tumor cells were added on days 0, 5, 10, 15 and 20 at an effector:target (E:T) ratio of 1:1. The residual tumor cells and persisting $\mathrm{T}$ cells were analyzed by FACS 5 days after each tumor addition.

\section{Cytokine analysis}

Supernatant collected from $24 \mathrm{~h}$ co-culture experiments was analyzed by an enzyme-linked lectin assay (ELLA) (R\&D System).

\section{In vivo experiments}

In vivo experiments were approved by the Italian Health Ministry (n. 88/2016-PR). Specifically, 6-week old NSG (NOD.Cg-Prkdcscid Il2rgtm1Wjl/SzJ; from Charles River) mice were engrafted intravenously (i.v.) with $0.2 \times 10^{6} \mathrm{CD}^{+} 0^{+}$ Karpas299-eGFP-FFLuc (NHL model) or $2 \times 10^{6} \mathrm{CD}^{+} 0^{+}$L428eGFP-FFLuc (HL model). After tumor engraftment, mice received an i.v. injection of effector $\mathrm{T}$ cells $\left(10 \times 10^{6} /\right.$ mouse). Tumor growth was evaluated using an IVIS imaging system (Perkin Elmer, USA). ${ }^{27}$ For tumor re-challenge, mice of the NHL model surviving until day +140 , were infused i.v. with $0.2 \times 10^{\circ}$ Karpas299-eGFP-FFLuc cells. Mice were followed for an additional 110 days, without effector T-cell administration. 
A

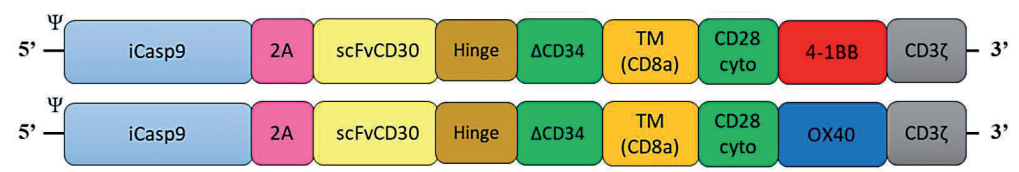

B

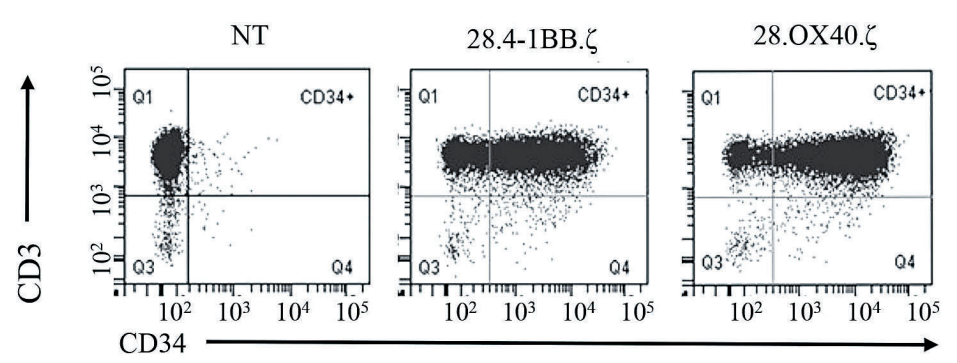

C

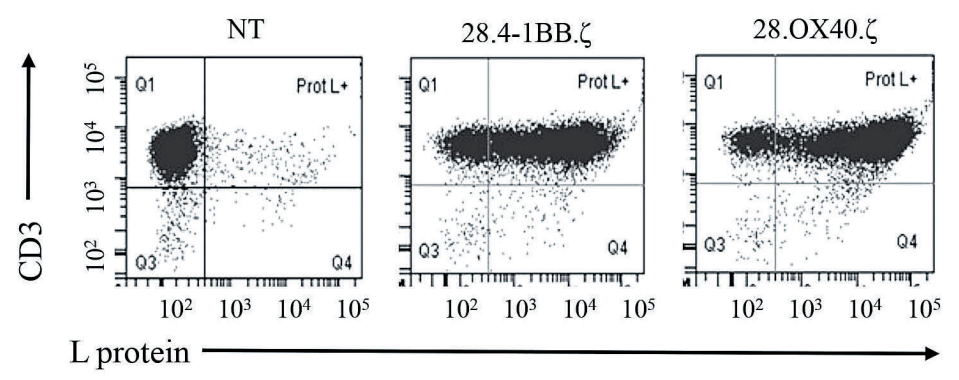

D

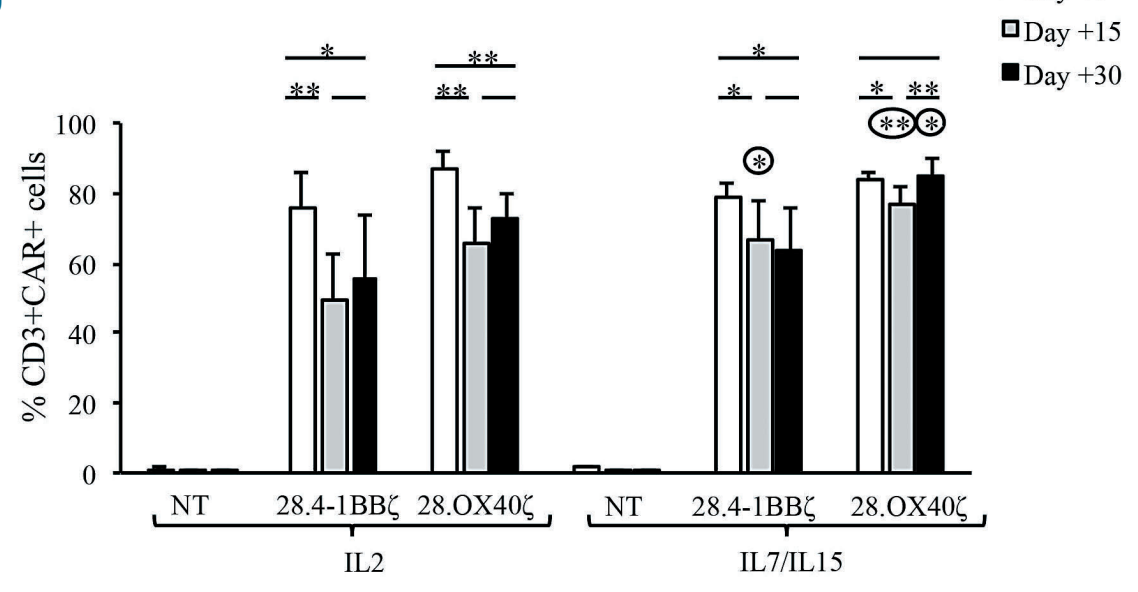

Figure 1. CAR.CD30 T cells with CD28.0X40 or CD28.4-1BB costimulation exhibit similar transduction levels and in vitro proliferation upon cytokine stimulation. (A) Diagram of the expression cassette of two third-generation CAR.CD30. The single-chain variable fragment (scFv) of CD30 was cloned in frame with CD8aTM, CD28 cytoplasmic moiety, and a second co-stimulatory domain represented by either 4-1BB or OX40, as well as the signaling domain CD3-zeta chain $(\xi)$. As a trackable marker, we added a peptide derived from human CD34 ( $\triangle \mathrm{CD} 34)$. A safety switch, namely inducible caspase- 9 (iCasp9), was also included in the vector constructs. (B) Flow-cytometry analyses in a representative donor showing chimeric antigen receptor (CAR) expression by detection of membrane CD34 in non-transduced (NT) T cells (negative control; left panel), $T$ cells genetically modified with CAR.CD30.ACD34.28.4.1BB. $\zeta$ (28.4.1BB.ร; middle panel) and T cells genetically modified with CAR.CD30.ACD34.CD28.0X40. (28.0X40.ร; right panel). (C) Flowcytometry analyses in a representative donor showing CAR expression using $\mathrm{L}$ protein to detect the ScFv in NT T cells (negative control; left panel), T cells genetically modified with 28.4.1BB. $\zeta$ (middle panel) and $T$ cells genetically modified with 28.0x40.5 (right panel). (D) Percentage of $\mathrm{CAR}^{+}$ $\mathrm{CD}^{+} \mathrm{T}$ cells during the time course of prolonged in vitro culture (day +5 white bars; day +15 gray bars; day +30 black bars), in NT, 28.4.1BB. $\zeta$ and 28.0X40. 6 grown in interleukin (IL)2 or in IL7/IL15. (E, F) Fold expansion of NT (empty circle), 28.4.1BB. (gray circle) and $28.0 \times 40 . \zeta$ (black circle) grown in IL2 (E) or IL7/IL15 (F) (dotted lines). Data from seven healthy donors are expressed as average \pm standard deviation. $* P \leq 0.05 ; \quad * * P \leq 0.01$; $* * * P \leq 0.001$. Circled asterisks refer to the difference between the T-cell populations grown in IL2 or in IL7/IL15.
E

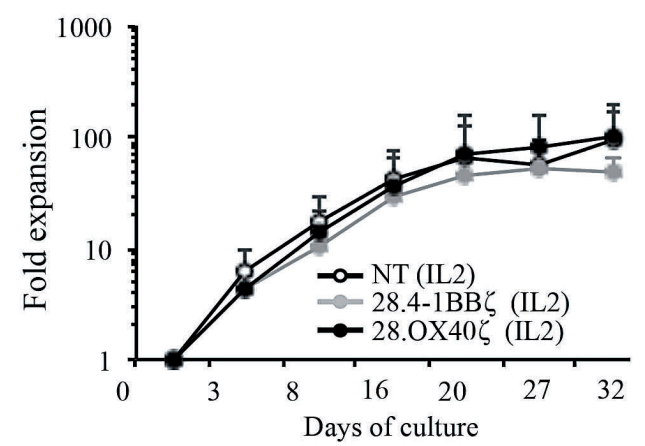

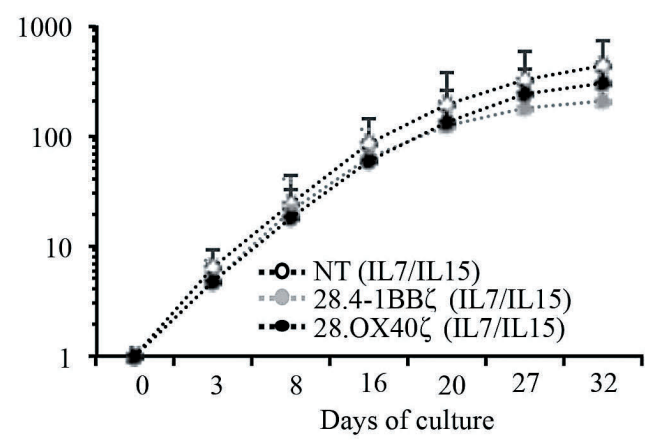




\section{Results}

\section{Characterization of CAR.CD30 T-cell in vitro activity}

CAR.CD30 molecules, either second-generation or third-generation (II-CAR or III-CAR), did not induce any proliferative changes in genetically modified $\mathrm{T}$ cells as compared to control non-transduced (NT) T cells (Online Supplementary Figure S1B). Moreover, regardless of the high level of CAR expression, detected with either antiCD34 (Figure 1B) or protein L (Figure 1C, Online Supplementary Figure $S_{1} C$ ), in vitro co-culture experiments showed that II-CAR.CD30.4-1BB was characterized by the worst anti-tumor activity compared to all the other configurations (Online Supplementary Figure S3A and B). The II-CAR.CD30.CD28 exerts a similar anti-lymphoma activity as the III-CAR also including the OX40 co-stimulatory domain; however, at a very low E:T ratio (1:8 effector T cells vs. L428 target cells), we observed that only the III-CAR showed significant anti-lymphoma activity compared to NT T cells (Online Supplementary Figure S3B). Moreover, we observed a superior trend, although not statistically significant, of a higher percentage of $\mathrm{CAR}^{+} \mathrm{T}$ cells (Online Supplementary Figure S1D) and interferon- $\gamma$ production upon $\mathrm{CD}^{+} 0^{+}$tumor encounter (Online Supplementary Figure $S 3 C$ and $D)$ in CAR.CD30.CD28.OX40 T cells with respect to II-CAR. Considering these data, together with the clinical evidence of the unsatisfactory outcome of patients receiving II-CAR.CD30 therapy, ${ }^{21,22}$ we continued our study focusing on III-CAR.CD30.

\section{CAR.CD30 T cells did not exert fratricidal activity}

The percentage of $\mathrm{CD} 30^{+} \mathrm{T}$ cells is high after in vitro stimulation, but then declines over time, with no significant difference between NT and CAR.CD30 T cells (Online Supplementary Figure S4A), indicating that CAR.CD30 T cells do not exert fratricidal activity. Moreover, CAR.CD30 T cells did not proliferate when stimulated by irradiated autologous activated T/CAR cells (Online Supplementary Figure S4B). Notably, mean fluorescence intensity (MFI) of CD30 in lymphoma cells was significantly higher with respect to activated $\mathrm{T}$ cells (Online Supplementary Figure S4C).

\section{Characterization of third-generation CAR.CD30 T cells in extended ex vivo culture}

We sought to verify whether different culture conditions could influence the percentage of total CAR ${ }^{+} T$ cells during standard and prolonged in vitro ex vivo expansion (day 30) to stress the system. CAR.CD30 T cells expanded in IL2 showed a significant reduction of CAR during extended in vitro culture (Figure 1D). The percentage of CAR.CD30.CD28.4-1BB decreased from $76.09 \% \pm 9.80 \%$ $($ day +5$)$ to $49.20 \% \pm 13.35$ (day $+15, P=0.002$ ), and to $55.93 \% \pm 18.09 \%$ after long-term culture (day +30 , $P=0.027$ with respect to day +5$)$. Similar results were also observed for CAR.CD30.CD28.OX40 T cells: $87.27 \% \pm$ $5.07 \%$ (day +5$), 65.15 \% \pm 10.92 \%$ (day $+15, P=0.003$ ); and $73.05 \% \pm 6.41 \%$ (day $+30, P=0.009$ compared to day +5 ). Moreover, IL7/IL15, compared to the IL2 condition, significantly improved the total percentage of $\mathrm{CAR}^{+} \mathrm{T}$ cells at day +15 (a standard time for CAR T-cell manufacturing); $76.84 \% \pm 5.45 \%$ CAR.CD30.CD28.OX40 and $66.44 \% \pm$ $10.95 \%$ CAR.CD30.CD28.4-1BB; $P=0.004$ and $P=0.02$, respectively).
While CAR.CD30 T cells did not show a significant proliferative advantage over NT T cells (Figure 1E and F), IL7/IL15 improved the expansion rate compared to IL2 (Online Supplementary Figure S5A-C), without any predominant T-cell receptor V $\beta$ family selection (Online Supplementary Figure $S 6 A$ and $B$ ). Independently of the costimulatory combination used, we did not observe a significant difference in the suicide gene inducible caspase 9 (iCasp9) activity, either in vitro (Online Supplementary Figure S7A) or in vivo (Online Supplementary Figure S7B-E). Details are provided in the Online Supplementary Results.

\section{CAR.CD30.CD28.0X40 T cells exert a superior in vitro anti-lymphoma activity compared to CAR.CD30.CD28.4-1BB T cells}

Both types of III-CAR.CD30 T cells significantly lysed the Karpas-299 NHL cell line (Figure 2A), as well as two HL cell lines (namely, HDML-2 and L428) (Figure 2B and $\mathrm{C}$, respectively). Cytotoxicity was specific, since negligible lysis was observed against CD30-negative BV173 cells (Figure 2D). The anti-lymphoma activity was also confirmed in a 7-day co-culture assay (Figure 2E-G).

Interestingly, at a very low E:T ratio, the anti-tumor activity of CAR.CD30.CD28.OX40 was superior to that exerted by CAR.CD30.CD28.4-1BB T cells: E:T ratio 1:8 T cells:Karpas-299 cells; $P=0.03$ (Figure $2 \mathrm{E}$ ) and $\mathrm{E}: \mathrm{T}$ ratios 1:16 and 1:32 T cells:HDML2 cells; $P=0.03$ and $P=0.01$, respectively (Figure 2F). The enhanced activity of CAR.CD30.CD28.OX40 T cells compared to that of CAR.CD30.CD28.4-1BB T cells was also demonstrated considering IFN $\gamma$ production upon stimulation by Karpas299 cells (Figure 2H) and HDML2 cells (Figure 2I). However, IFN $\gamma$ production was comparable when we used the cell line L428 as the target (Figure 2J).

\section{Long-term tumor control and CAR.CD30 T-cell} selection in a "stressed" co-culture model

To evaluate the lytic potential of CAR.CD30 T cells, we "stressed" the co-culture conditions by re-challenging Karpas-299 cells every 5 days (Figure 3A). At each timepoint, we evaluated the percentage of residual tumor, CAR expression and its relative MFI, the relative production of IFN $\gamma$, TNF $\alpha$, IL2 and IL10 (24 h after each tumor re-challenge), the $\mathrm{CD}^{+} / \mathrm{CD}^{+}$distribution and the memory/exhaustion profile.

Both types of III-CAR.CD30 T cells exhibited high tumor control even after multiple exposures to Karpas299. Although we did not observe significant differences in the in vitro anti-tumor activity between constructs, CAR.CD30.CD28.4-1BB T cells showed high intra-donor variability in terms of tumor elimination. By contrast, CAR.CD30.CD28.OX40 T cells were endowed with more stable and predictable lymphoma recognition and killing (residual tumor cells at day $+20: 8.6 \% \pm 5.3 \%$ for $28.0 \times 40 . \zeta$ and $27.9 \% \pm 29.5 \%$ for $28.4-1 \mathrm{BB} . \zeta \mathrm{T}$ cells) (Figure $3 \mathrm{~B}$ ). Interestingly, while the percentage of $\mathrm{CAR}^{+}$ cells increased after the first tumor encounter, subsequent tumor re-challenging negatively affected the percentage of residual CAR.CD30.CD28.4-1BB T cells in the in vitro culture $(93.8 \% \pm 2.7 \%$ at day +5 and $63.0 \% \pm 32.30 \%$ at day $+20 ; P=0.041$ ) (Figure 3C); by contrast, the percentage of CAR.CD30.CD28.OX40 T cells remained stable over time (Figure $3 \mathrm{C}$ ). This phenomenon led to a significant difference of $\mathrm{CAR}^{+}$cells at day +20 between the two types of CAR T cells $(P=0.043)$ (Figure 3C). 


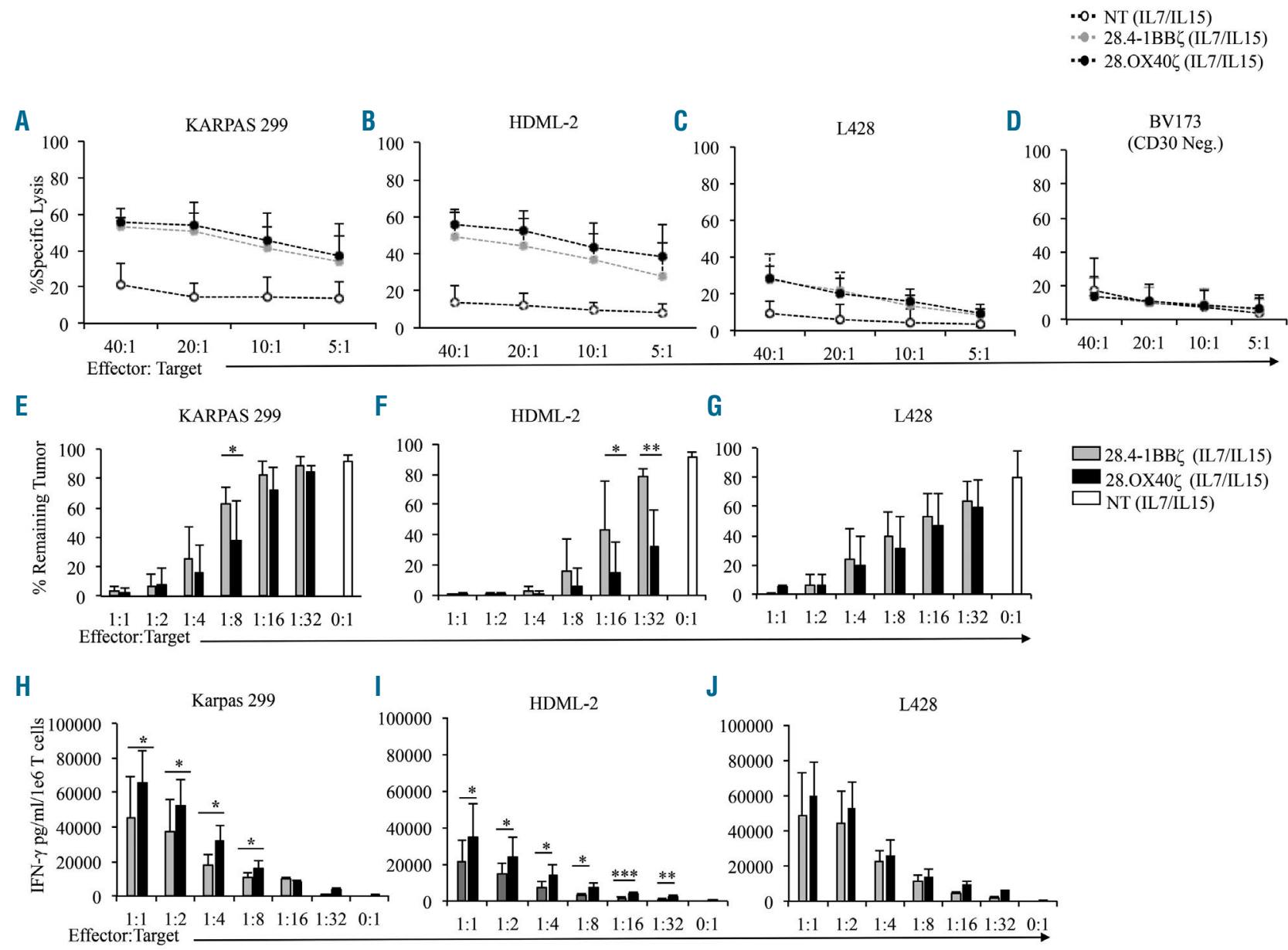

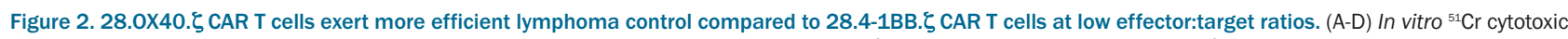

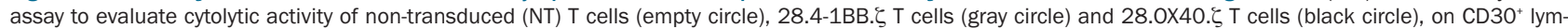
phoma cell lines, namely Karpas-299 (A), HDML-2 (B) and L428 (C) cells, as well as on the CD30- leukemia cell line BV173 (D). (E-G) The long-term 7-day co-culture

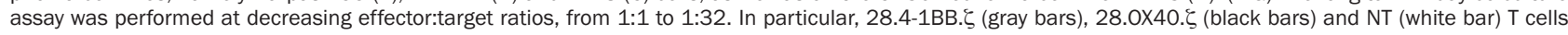
were co-cultured with CD30+ Karpas-299 (E), HDML-2 (F) and L428 (G) cell lines. (H-J) Interferon-gamma (IFN- $\gamma$ ) production after $24 \mathrm{~h}$ of co-culture was measured. Data from seven healthy donors are expressed as average \pm standard deviation. $* P \leq 0.05 ; * * P \leq 0.01 ; * * * P \leq 0.001$ and $* * * * P \leq 0.0001$.

Similarly, the higher CAR MFI observed since day 0 in CAR.CD30.CD28.OX40 T cells compared to CAR.CD30.CD28.4-1BB T cells was retained stably over time during "stressed" co-culture experiments (Figure 3D).

Furthermore, CAR.CD30.CD28.OX40 T cells showed a significantly higher activation profile over time after tumor exposure compared to CAR.CD30.CD28.4-1BB T cells, in terms of cytokine production (Figure 3E-G), with a lower level of IL10 (produced by Karpas-299 cells, as shown by the red bar in Figure $3 \mathrm{H}$.

\section{Dynamic evolution of memory and exhaustion profiles in response to cytokine or tumor stimulation in CAR.CD30 T cells}

At day +15 after transduction, most expanded CAR T cells cultured with IL2 had an effector memory (EM) phenotype (Figure 4A), with no substantial differences observed when compared with NT T cells. IL7/IL15 significantly reduced the central memory (CM) compartment, in favor of EM and effector terminal (EMRA) cells in both CAR.CD30. Interestingly, the "stressed" co-culture significantly changed the profile of CAR $T$ cells.
After 5 days of co-culture the naïve compartment decreased rapidly from $26.1 \% \pm 13.0 \%$ to $2.6 \% \pm 1.3 \%$ for $28 . \mathrm{OX} 40 . \zeta(P=0.029)$ and from $30.1 \% \pm 16.5 \%$ to $4.0 \% \pm 3.0 \%$ for $28.4-1 \mathrm{BB}$. $\zeta \mathrm{T}$ cells $(P=0.034)$. Tumor-cell encounter significantly modulated CAR T-cell subsets, while the profile of NT $\mathrm{T}$ cells compared to day 0 remained stable. In particular, the naive subset was significantly reduced in both CAR T-cell types, whereas the CM subset increased from day 0 to day +20 (see Figure 4B).

We sought to evaluate the exhaustion profile modulation of CAR T cells after tumor challenge. Although no difference was recorded at day 0 (Figure 4C), we observed a significant upregulation of LAG3, TIM3, and PD-1 receptors after the first tumor-cell exposure, with CAR.CD30.CD28.OX40 T cells showing higher expression of TIM3 over time compared to CAR.CD30.CD28.4-1BB cells. Nevertheless, TIM3 was also significantly upregulated in NT T cells upon tumor exposure (Figure 4D). Interestingly, no differences were observed between III-CAR-T-cell types in terms of percentage of exhausted cells with triple positivity for LAG3/TIM3/PD-1 (Figure 4D). 
A

KARPAS 299 re-challenging

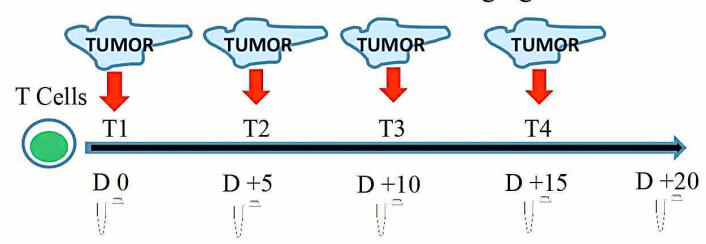

C

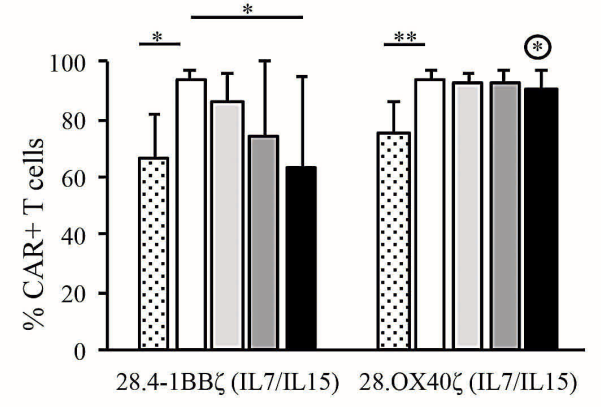

E

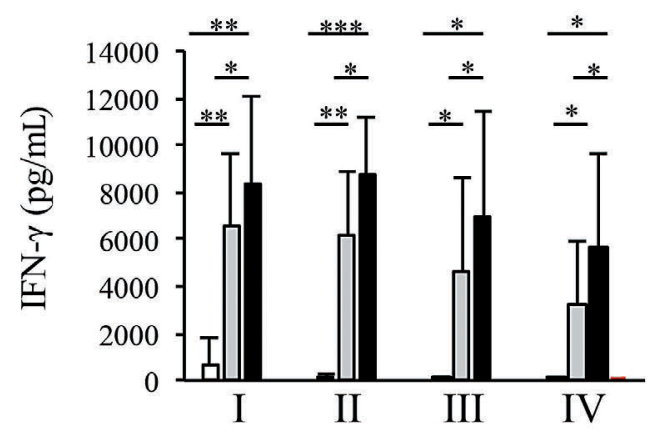

G

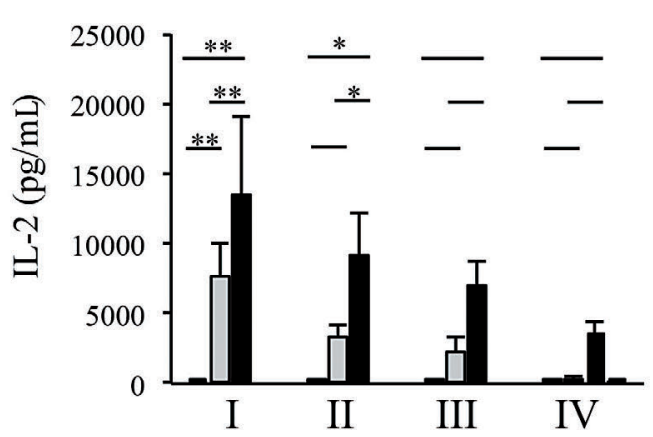

B

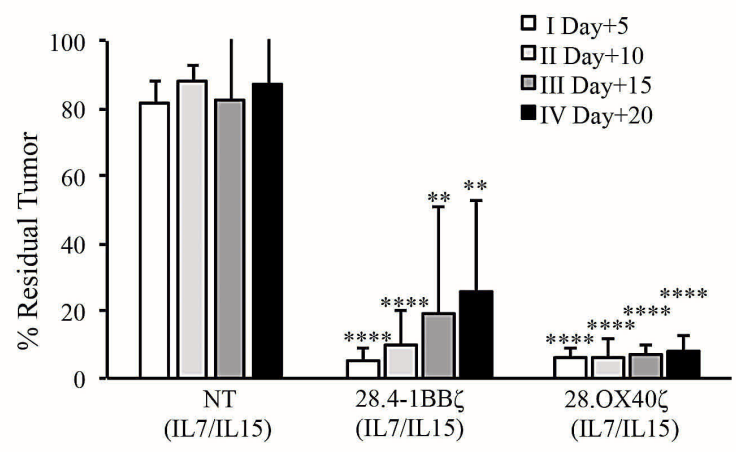

D

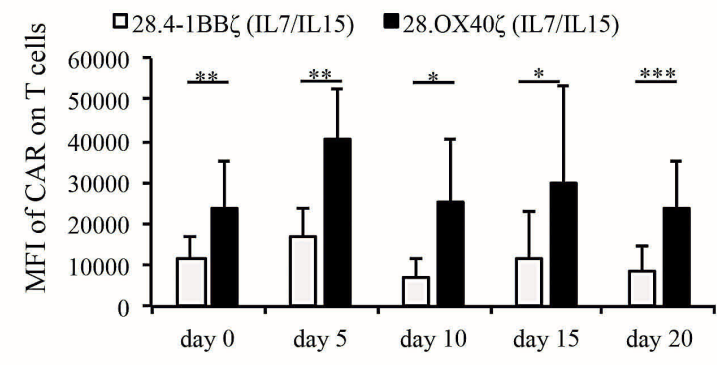

F

$\square$ 28.4-1BB (IL7/IL15)

28.OX40 (IL7/IL15)

$\square$ NT (IL7/IL15)

Tumor

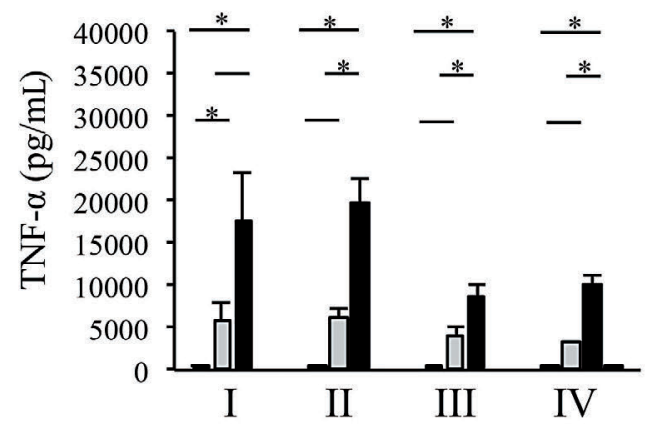

H

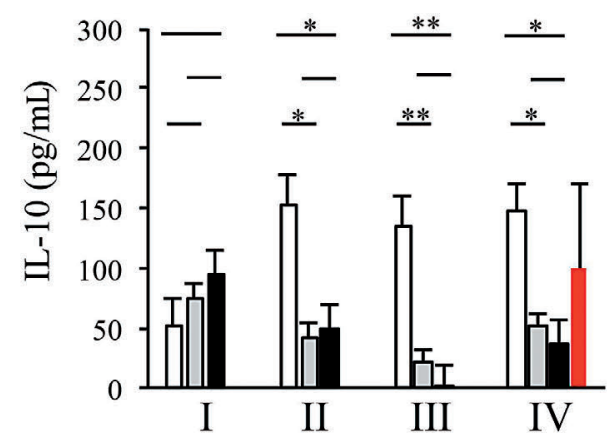

Figure 3. Long-term tumor control and CAR.CD30 T-cell selection in the "stressed" co-culture in vitro assay model. (A) The panel shows the experimental design of the "stressed" co-culture. (B) Residual CD $30^{+}$tumor cells were quantified during the "stressed" co-culture after addition of tumor cells every 5 days. Data are shown for day +5 (white bars), day +10 (light gray bars), day +15 (dark gray bars) and day +20 (black bars). (C) The percentage of CAR ${ }^{+} \mathrm{T}$ cells was quantified during the "stressed" co-culture. Data are shown for day 0 (dotted bars, referring to the percentage of CAR ${ }^{+}$T cells before the first addition of tumor cells), day +5 (white bars), day +10 (light gray bars), day +15 (dark gray bars) and day +20 (black bars). (D) Mean fluorescence intensity (MFI) analysis of CAR expression on $28.4-1 B B$. $\zeta$ T cells (gray bars) and $28.0 \times 40 . \zeta$ T cells (black bars). (E) Interferon (IFN)- $\gamma$, (F) tumor necrosis factor (TNF)- $\alpha,(\mathrm{G})$ interleukin (IL)-2 and (H) IL-10 production was analyzed in supernatants collected $24 \mathrm{~h}$ after addition of tumor cells to the culture. Data from seven healthy donors are expressed as average \pm standard deviation. $* P \leq 0.05$; $* * P \leq 0.01 ; * * * P \leq 0.001$ and $* * * * P \leq 0.0001$. Circled asterisks refer to the difference between 28.0X40. $\zeta$ and 28.4-1BB. $\zeta \mathrm{T}$ cells. 
A

$\begin{array}{ll} & \square^{\mathrm{NT}} \\ \text { Modulation by cytokines } & \square_{28.4-1 \mathrm{BB} \zeta(\mathrm{CAR}+)} \\ & \end{array}$

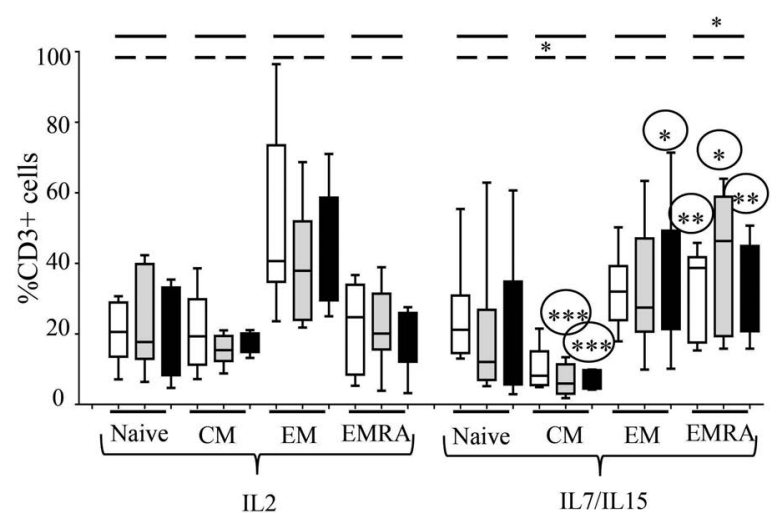

B

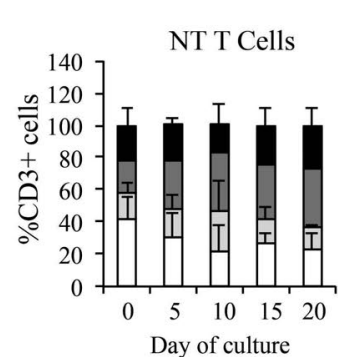

Modulation by tumor (Karpas 299)

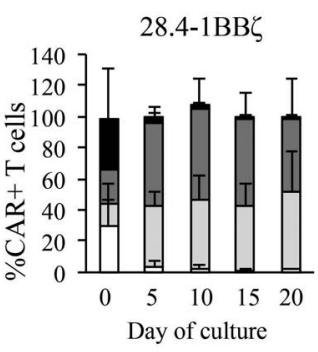

Day of culture

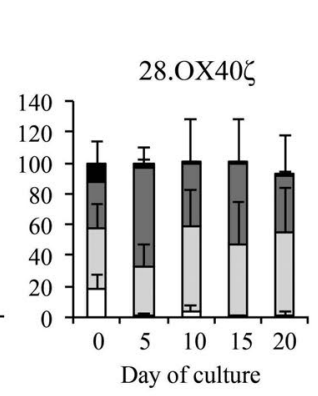

Figure 4. Memory and exhaustion profiles in CAR.CD30 T cells. (A) Non-transduced (NT; white bars), 28.4.1BB. (light gray bars) or $28.0 \times 40 . \zeta$ (dark gray bars) T cells, expanded in interleukin (IL)2 or IL7/IL15 cytokines were analyzed by flow-cytometry at day +15 of in vitro culture to establish the percentage of naïve, central memory (CM), effector memory (EM) and effector terminal (EMRA) $\mathrm{CD3}^{+}$cell subsets. (B) Analysis of naîve (white bars), CM (light gray bars), EM (dark gray bars) and EMRA (black bars) $\mathrm{CD}^{+}$cell subsets in the long-term "stressed" co-culture for NT (left panel), 28.4-1BB. 5 (middle panel) and 28.0X40.ร (right panel) T cells. (C) NT (white bars), 28.4.1BB. (light gray bars) or 28.0X40. (dark gray bars) T cells expanded in IL2 or IL7/IL15 cytokines were analyzed to assess their exhaustion profile by the expression of the three markers PD1, LAG3 and TIM3. (D) Analysis of the exhaustion profile in NT (left panel), 28.4.1BB. $\zeta$ (middle panel) and $28.0 \times 40 . \zeta$ (right panel) $\mathrm{T}$ cells during the long-term "stressed" co-culture assay at day 0 (white dotted bars), Time I: day +5 (white bars), time II: day +10 (light gray bars), time III: day +15 (dark gray bars) and time IV: day +20 (black bars). Data from four healthy donors are expressed as average \pm standard deviation. ${ }^{*} P<0.05$; $* * P<0.001$. Circled asterisks refer to the difference between the T-cell population grown in IL2 or in IL7/IL15.

EMRA

$\square \mathrm{EM}$

$\square \mathrm{CM}$

$\square$ Naive

C Modulation by cytokines

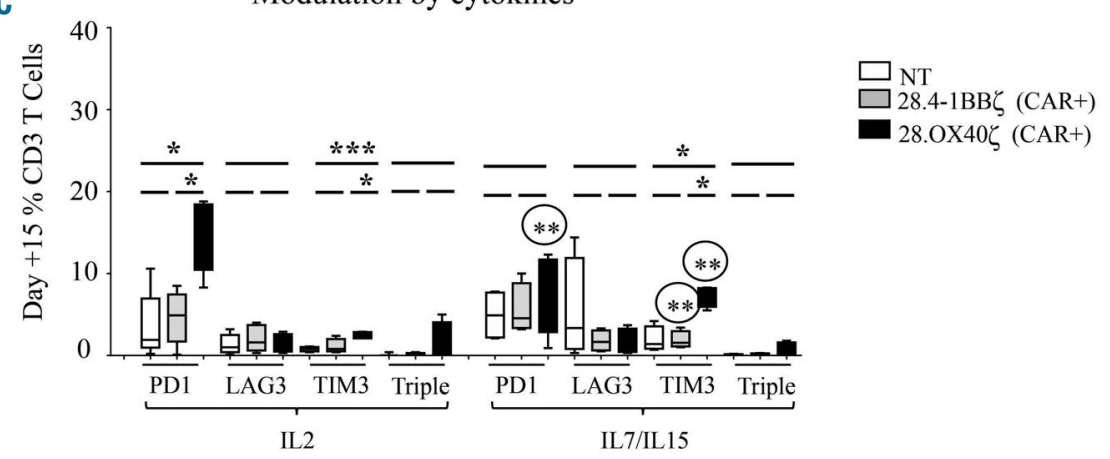

D

Modulation by tumor (Karpas 299)

ㅁ. Day 0

$\square$ I Day +5

II Day+10

NT

28.4-1BBל

$28.0 \times 40 \zeta$

口III Day+15
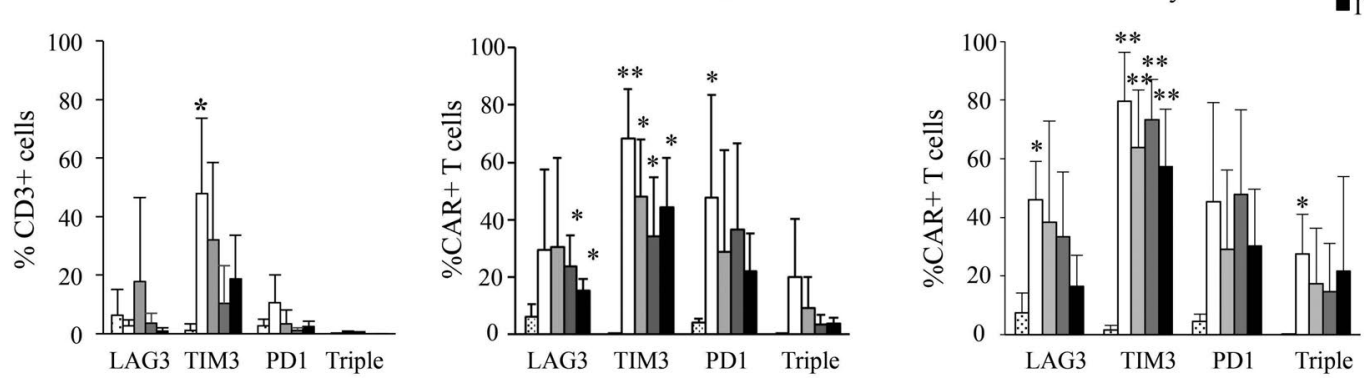
Dynamic evolution of the CD4/CD8 ratio in response to cytokine or tumor stimulation of CAR.CD30 T cells

We also evaluated the dynamic evolution of $\mathrm{CD}^{+}$and $\mathrm{CD} 8^{+} \mathrm{T}$ cells during prolonged in vitro culture in the presence of either cytokine stimulation (days $+5,+15$ and +30 after transduction) or exposure to tumor cells. As shown by CFSE analysis, we observed that $\mathrm{CD} 8^{+} \mathrm{T}$ cells had a proliferative advantage compared to $\mathrm{CD}^{+} \mathrm{T}$ cells, whether stimulated with IL2 (Figure 5A) or IL7/IL15 (Figure 5B). This observation correlated with the evidence that, during prolonged in vitro culture, in the presence of cytokine stimulation, the CAR.CD30 T-cell population was significantly enriched for $\mathrm{CD}^{+}$cells (Figure $5 \mathrm{C}$ and D). Indeed, irrespectively of cytokine usage (IL2 or IL7/IL15) or choice of co-stimulatory domains (28.OX40 vs. 28.4-1BB), $\mathrm{CD}^{+}{ }^{+} \mathrm{T}$-cell percentage decreased over time up to day +30 of culture, compared with the percentage on day +5 . Notably, the $\mathrm{CD} 4^{+} / \mathrm{CD} 8^{+} \mathrm{T}$-cell ratio remained stable over time when CAR.CD30 T cells were exposed to sequential re-challenge with Karpas-299 (Figure 5E and F), suggesting that repeated tumor stimulation induces equal expansion of CD4 and CD8 CAR ${ }^{+} \mathrm{T}$ cells.

\section{Evaluation of the efficacy of CAR.CD30 T-cells in a mouse model of Hodgkin lymphoma}

We next assessed whether the choice of the co-stimulatory combination or cytokines used during in vitro expansion might influence the in vivo activity of CAR.CD30 T cells against L428 cells (Figure 6A). Bioluminescence in HL-tumor-bearing mice, treated with NT T cells, rapidly increased up to $5 \log$ in less than 50 days (Figure $6 \mathrm{~B}$ and C) and mice either died or were sacrificed due to poor conditions. Macroscopic analysis of sacrificed mice showed large tumor masses located preferentially in the liver. HL-tumor-bearing mice treated with 28.4-1BB. $\zeta$ (IL2) survived on average significantly longer $(79 \pm 10$ days) compared with mice treated with NT (IL2) (Figure $6 \mathrm{D} ; 52 \pm 9$ days, $P=0.008$ ). The use of IL7/IL15 did not improve the anti-tumor effect of $28.4-1 \mathrm{BB} . \zeta$, in terms of both bioluminescence signal (Figure $6 \mathrm{~B}$ and $\mathrm{C}$ ) and overall survival (Figure 6D). The median survival of HL-tumorbearing mice treated with $28.0 X 40 . \zeta$ (IL2) was significantly better than that of mice treated with either NT (IL2) $(P=0.009)$ or $28.4-1 \mathrm{BB} . \zeta$ (IL2) $(P=0.008)$. Notably, the best outcome was observed in mice given 28.OX40.ร T cells grown in the presence of IL7/IL15, as three out of five mice were still alive at the experimental end-point of day +165 (Figure 6D).

Although mice treated with NT T cells showed a significant increase in human circulating $\mathrm{CD} 45^{+} \mathrm{CD} 3^{+}$cells with a peak evaluated at day +56 (Figure $6 \mathrm{E}$ ), we did not observe any tumor control. Only in mice given 28.OX40.ร T cells did we observe a long-lasting persistence of circulating CAR T cells up to day +130 (Figure 6F). The percentage of circulating 28.OX40.ร T cells (Figure 6 F) remained stable during the first 100 days. On day +165 , we found residual circulating $\mathrm{T}$ cells in only two out of four treated mice $(0.06 \% \pm 0.02 \%)$ although all four mice were cured at this time. In these two mice, circulating CAR.CD30 T cells were equally distributed between $\mathrm{CD}^{+}$and $\mathrm{CD}^{+}$, as $\mathrm{CM}$ and EM (Online Supplementary Figure S8). These data further confirmed in vitro results about the superiority of IL7/IL15 over IL2 in expanding CAR T cells. Moreover, 28.4-1BB.ร T cells showed only slight in vivo expansion and persistence
(Figure $6 \mathrm{~F}$ ). We also correlated the kinetics of tumor growth (bioluminescence) and CAR T-cell expansion, observing that mice receiving $28.0 X 40 . \zeta \mathrm{T}$ cells showed a significant reduction of tumor burden concomitant with the $\mathrm{CD}^{+}$peak (Online Supplementary Figure S9A and B). By contrast, in mice treated with $28.41 \mathrm{BB} . \zeta$, the kinetics of circulating $\mathrm{T}$ cells $\left(\mathrm{CD} 45^{+} \mathrm{CD}^{+}\right)$, as well as of $\mathrm{CAR}^{+} \mathrm{T}$ cells, did not correlate with bioluminescence signaling (Online Supplementary Figure S9C and D).

\section{Evaluation of persistence and establishment of long-term immunological memory in the re-challenged mouse model of non-Hodgkin lymphoma}

We then evaluated in vivo efficacy, persistence and establishment of long-term memory of CAR.CD30 T cells (IL7/IL15) in a Karpas-299 xenograft model with tumor rechallenge (Figure 7A). While tumor bioluminescence in the group treated with NT T cells progressively increased up to $5 \log$ in less than 40 days (Figure $7 \mathrm{~B}$ and $\mathrm{C}$ ), in mice receiving $28.0 X 40 . \xi \mathrm{T}$ cells we observed significant tumor control $(P=0.0075)$ as measured by reduction of the bioluminescence signal. The median survival of mice treated with NT T cells was 45.5 days, while $30 \%$ of mice given $28.4-1 \mathrm{BB} . \zeta$ and $60 \%$ of mice given $28.0 X 40 . \zeta$ experienced long-term tumor control (Figure 7D). In particular, the median survival of mice treated with 28.4-1BB. $\zeta$ was 58 days $(P=0.05)$, and undetermined for mice given 28.OX40.ร $(P=0.0002)$ (Figure 7D).

After 140 days, cured mice were re-challenged i.v. with Karpas-299 cells, and followed for an additional 100 days. Bioluminescence analysis showed rapid progression of the tumor in control mice (CTR mice), as well as in 28.41BB. $\zeta$-treated mice. In contrast, in 28.OX40.ร-treated mice, after an initial expansion of the tumor for the first 40 days, at day +100 (at day +240 overall), four of six mice were tumor-free, which translated into a statistically significant survival benefit (Figure 7D). To confirm the establishment of long-term immunological memory, we analyzed circulating $\mathrm{CD} 45^{+} \mathrm{CD}^{+}$human cells over time in treated mice. We observed significantly greater expansion of circulating $\mathrm{T}$ cells in the first week after effector $\mathrm{T}$-cell infusion in mice treated with 28.OX40.5 CAR T cells $(2.49 \% \pm 1.03 \%)$ (Figure 7E) compared to mice given 28.4 1BB. $\zeta$ CAR T cells $(0.27 \% \pm 0.11 \% ; P<0.001)$ or NT T cells $(0.35 \% \pm 0.07 \% ; P=0.005)$.

Interestingly, at day +132 (before the second infusion of tumor cells), the number of circulating CAR $T$ cells was negligible in all cohorts. Forty days after tumor re-challenge (day +180$)$, we observed a significant and impressive expansion of circulating human $\mathrm{CD} 45^{+} \mathrm{CD} 3^{+}$cells in mice treated with 28.OX40.ร T cells (Figure 7E) compared to that in mice receiving 28.4-1BB. $\zeta \mathrm{T}$ cells. After re-expansion, $\mathrm{CDB}^{+}$cells were significantly enriched in 28.OX40.ร CAR ${ }^{+}$ T cells (Figure 7F, Online Supplementary Figure S10A-H). This enrichment was tumor-specific, since the complete eradication of the second tumor infusion was associated with a simultaneous decline of circulating $28.0 X 40.5 \mathrm{~T}$ cells to an undetectable percentage, as measured at day +221 (Figure 7E, Online Supplementary Figure S10A-H).

Finally, while human CAR.CD30 T cells were found to infiltrate tumor (Online Supplementary Figure S11A) independently of the co-stimulatory combination present in the CAR construct, the infiltration observed in 28.OX40.5 (IL7/15) T-cell-treated mice was greater than that in all other conditions (Online Supplementary Figure S11B and C). 
A

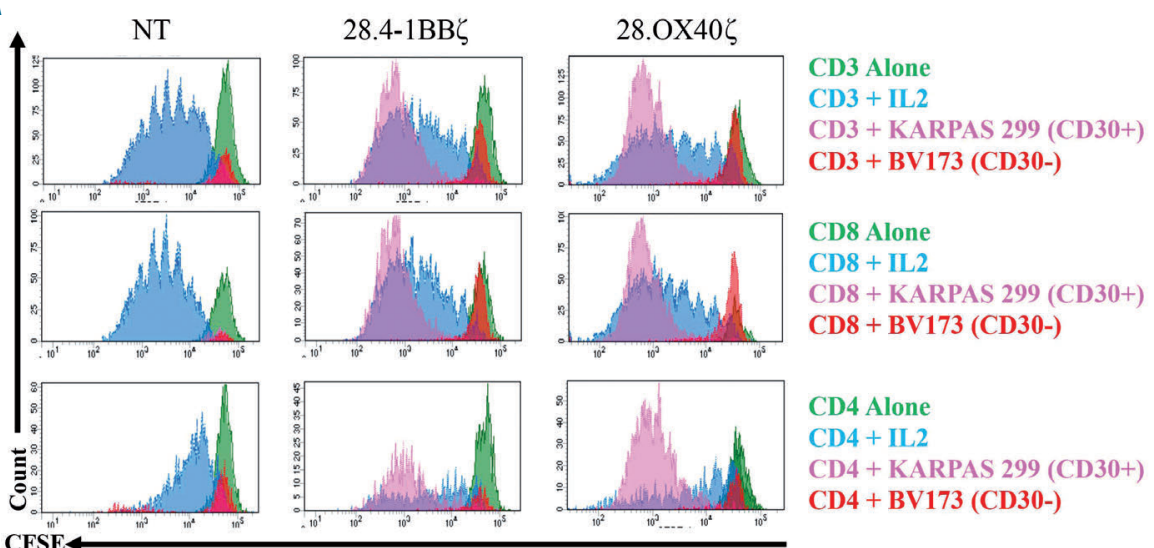

B

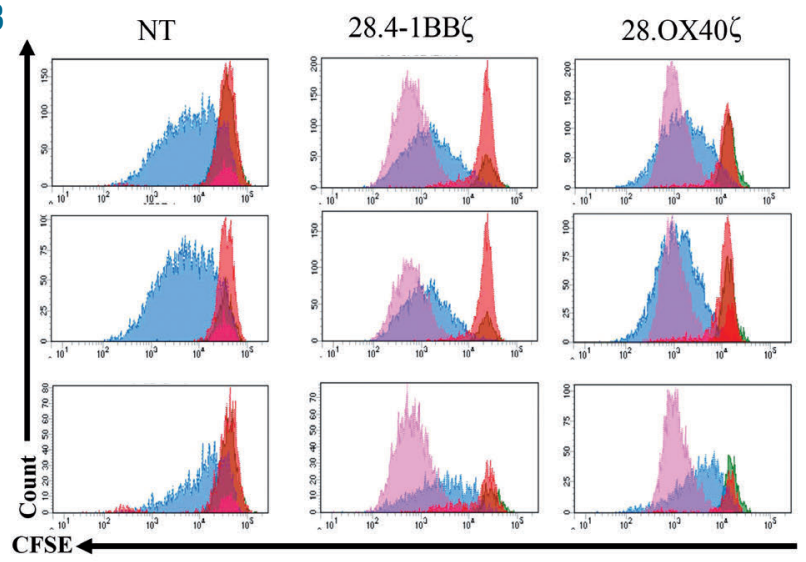

CD3 Alone

CD3 + IL 7/IL15

CD3 + KARPAS 299 (CD30+)

CD3 + BV173 (CD30-)

CD8 Alone

CD8 + IL7/IL15

CD8 + KARPAS 299 (CD30+)

CD8 + BV173 (CD30-)

CD4 Alone

CD4 + IL7/IL15

CD4 + KARPAS 299 (CD30+)

CD4 + BV173 (CD30-)

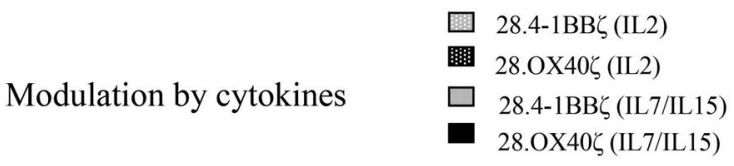

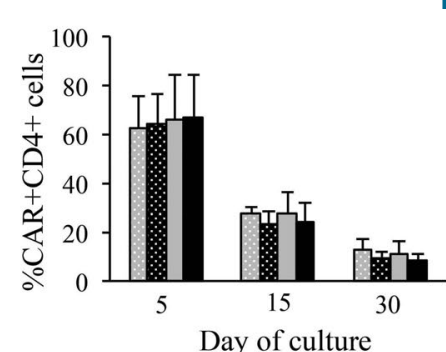

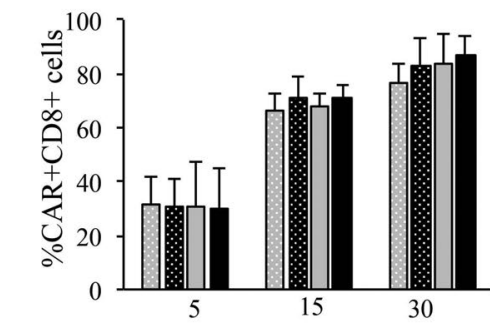

Day of culture

Modulation by tumor (Karpas 299)

$\mathbf{E}$

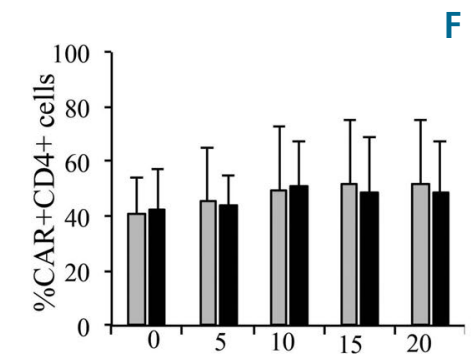

Day of culture

$\mathbf{F}$

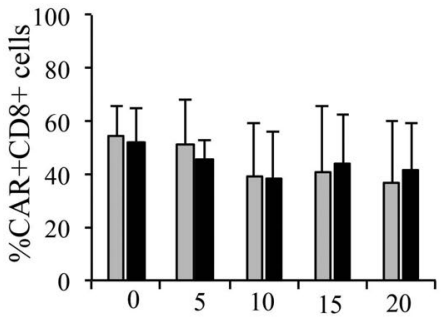

Day of culture
28.4-1BB 5

$28.0 \times 405$
Figure 5. The CD4/CD8 CAR.CD30 T-cell ratio is modulated by both cytokines and $\mathrm{CD} 30^{+}$ tumor cells. (A) Analysis of the proliferation of non-transduced (NT, left panels), 28.4.1BB. $\zeta$ (middle panels) or $28.0 \times 40 . \zeta$ (right panels) $\mathrm{T}$ cells, unstimulated (green histograms), stimulated with interleukin (IL)2 cytokine (blue histograms), stimulated with $\mathrm{CD} \mathrm{O}^{+}$Karpas-299 cells (pink histograms) and stimulated with CD30- BV173 cells (red histograms). (B) Analysis of the proliferation of NT (left panels),

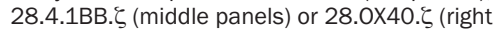
panels) $T$ cells, unstimulated (green histograms), stimulated with IL7-IL15 cytokine (blue histograms), stimulated with $\mathrm{CD} 30^{+}$ Karpas-299 cells (pink histograms) and stimulated with CD30- BV173 cells (red histograms). (C, D) Flow cytometric analysis of $\mathrm{CD} 4^{+}$and CD8 ${ }^{+} \mathrm{CAR}^{+} \mathrm{T}$-cell percentage evaluated during in vitro exposure to IL2 (28.4.1BB. $\zeta$, dotted gray bars; 28.0X40., dotted black bars), or IL7-IL15 (28.4.1BB. , gray bars; $28.0 \times 40 . \zeta$, black bars). (E, F) Flow cytometric analysis of $\mathrm{CD}^{+}$and $\mathrm{CD}^{+}{ }^{+}$T-cell percentage in CAR.CD30 $\mathrm{T}$ cells evaluated during long-term "stressed" co-culture for $28.4 .1 \mathrm{BB} . \zeta$ (gray bars) and $28.0 \times 40 . \zeta$ (black bars). Data from seven healthy donors are expressed as average \pm standard deviation. 


\section{Discussion}

To date, clinical trials conducted in adults with relapsed/refractory $\mathrm{CD} 0^{+}$lymphoma, using IICAR.CD30 T cells, led to suboptimal outcomes..$^{21,22}$ As in patients with B-cell acute lymphocytic leukemia receiving CAR.CD19 T cells, ${ }^{29}$ a clear correlation between CAR T- cell persistence in peripheral blood and clinical benefit was reported in $\mathrm{HL}$ and $\mathrm{NHL},{ }^{21,30}$ highlighting the need for further optimization. We, therefore, attempted to include a novel scFv, derived from the high-affinity anti-CD30 mouse AC10 monoclonal antibody, in our CAR construct. ${ }^{25}$ In the context of high-affinity CAR, major concerns are related to CAR T-cell overstimulation, induction

A

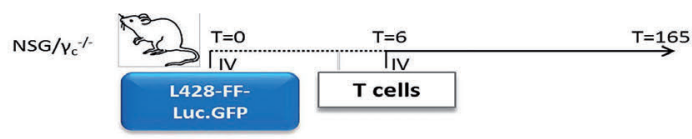

B NT 28.4-1BB $\zeta 28.0 \times 40 \zeta \quad$ NT $28.4-1 \mathrm{BB} \zeta .28 .0 \times 40 \zeta$
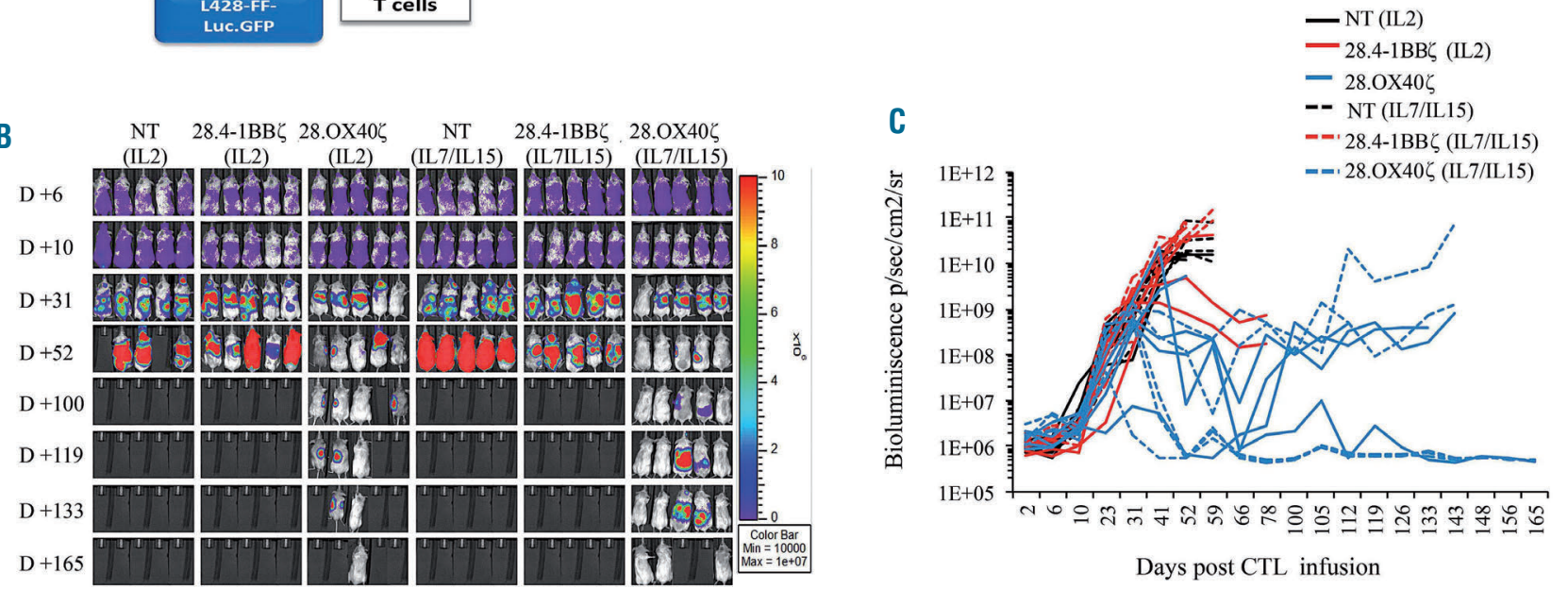

D

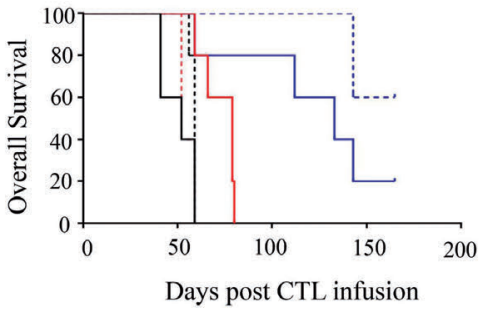

\begin{tabular}{|c|c|}
\hline & $P$ value \\
\hline NT vs 28.4-1BB $\zeta$ (IL2) & 0,009 \\
\hline NT vs $28.0 X 40 \zeta$ (IL2) & 0,009 \\
\hline $28.0 X 40 \zeta$ vs $28.4-1 \mathrm{BB} \zeta \quad$ (IL2) & 0,008 \\
\hline NT vs 28.4-1BB $\zeta$ (IL7/IL15) & ns \\
\hline NT vs $28.0 X 40 \zeta(\mathrm{IL} 7 / \mathrm{IL} 15)$ & 0,035 \\
\hline $28.0 X 40 \zeta$ vs $28.4-1 \mathrm{BB} \zeta(\mathrm{IL} 7 / \mathrm{IL} 15)$ & 0,002 \\
\hline $28.0 X 40 \zeta$ (IL2) vs $28.0 \times 40 \zeta$ (IL7/LL15) & ns \\
\hline $28.4-1 \mathrm{BB} \zeta$ (IL2) vs $28.4-1 \mathrm{BB} \zeta$ (IL 7/IL15) & 0,008 \\
\hline
\end{tabular}

E

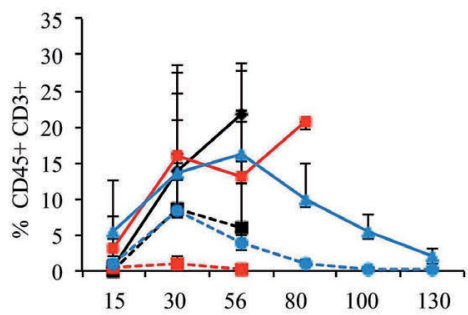

Days post CTL infusion
$\mathrm{F}$

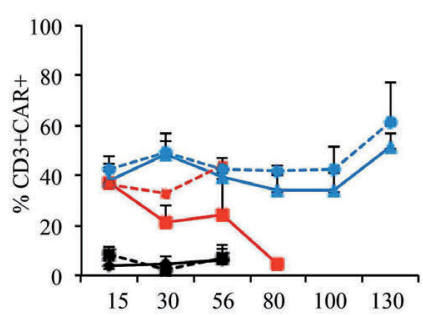

Days post CTL Infusion

Figure 6. Mouse model of Hodgkin Iymphoma to evaluate anti-lymphoma activity of CAR.CD30 T cells generated and expanded in the presence of interleukin-2 or interleukin-7/interleukin-15. (A) The schema shows the in vivo xenograft immunodeficient mouse model, in which Hodgkin lymphoma (HL) L428-eGFP-FFLuc cells were systemically infused into NSG mice. Effector cells were infused intravenously at the time of tumor establishment (day +6), as assessed by IVIS imaging. Blood was collected periodically from the mice. (B) IVIS imaging of tumor growth from day +6 to day +165 (end of experiment). (C) Bioluminescence of each single xenograft mouse treated with non-transduced (NT) T cells and interleukin (IL)2 (black line; 5 mice); 28.4-1BBל T cells (IL2) (red line; 5 mice); $28.0 X 40 \xi$ T cells (IL2) (blue line; 5 mice); NT T cells (IL7/IL15) (dotted black line; 5 mice); 28.4-1BB $\zeta$ T cells (IL7/IL15) (dotted red line; 5 mice) and 28.0X40 $\zeta$ T cells (IL7/IL15) (dotted blue line; 5

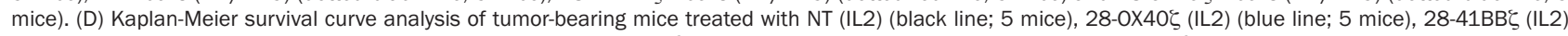
(red line; 5 mice), NT (IL7/IL15) (dotted black line; 5 mice), 28-0X40 (IL7/IL15) (dotted blue line; 5 mice) and 28-41BBC (IL7/IL15) (dotted red line; 5 mice). Pvalues are reported in the table. (E) Average percentages of circulating human CD45+ CD3 ${ }^{+} \mathrm{T}$ cells in mice treated with NT (IL2) (black line; 5 mice), 28-OX40 5 (IL2)

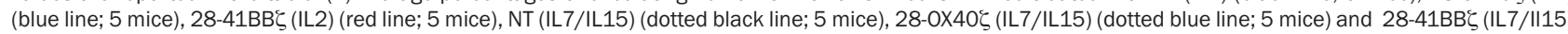
(dotted red line; 5 mice). (F) Average percentages of circulating human CD3 ${ }^{+}$CAR ${ }^{+}$T cells in mice treated with NT (IL2) (black line; 5 mice), 28-OX40 $\zeta$ (IL2) (blue line; 5 mice), 28-41BBC (IL2) (red line; 5 mice), NT (IL7/IL15) (dotted black line; 5 mice), 28-OX40广 (IL7/IL15) (dotted blue line; 5 mice) and 28-41BBC (IL7/II15) (dotted red line; 5 mice). 
A

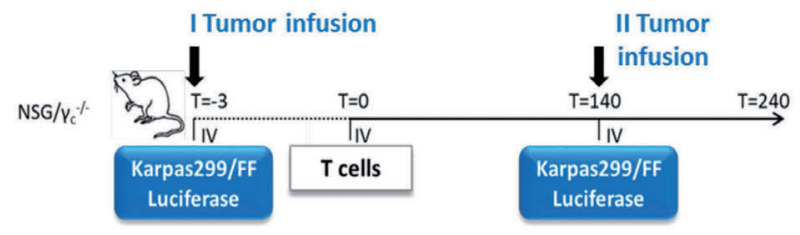

B

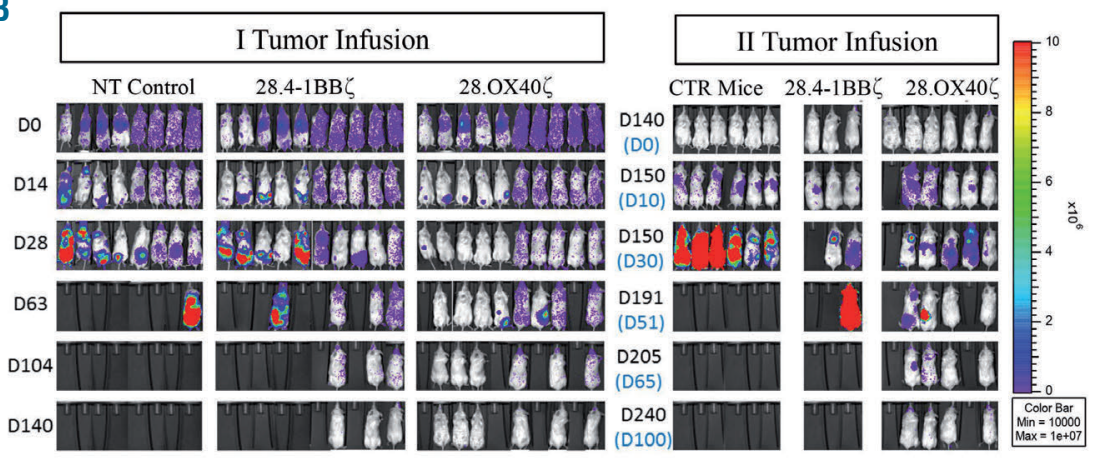

C

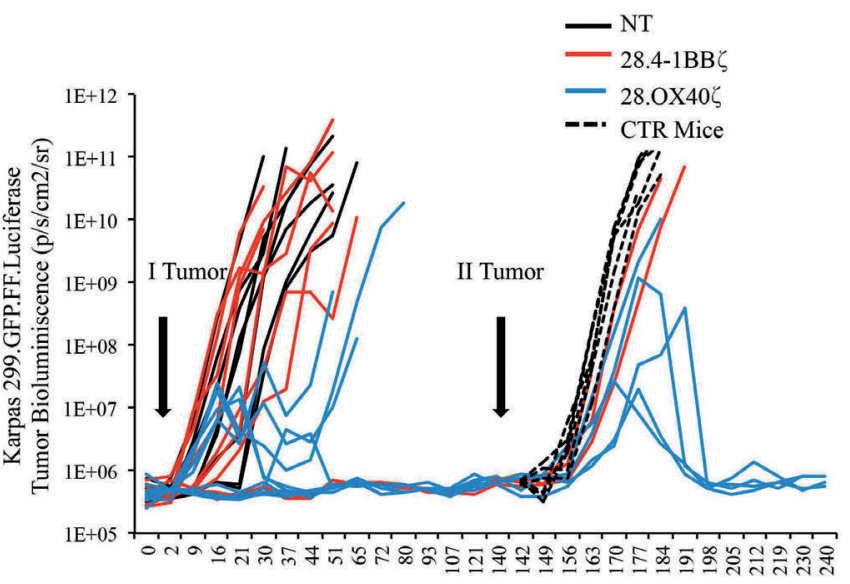

Days after $\mathrm{T}$ cell Infusion

D
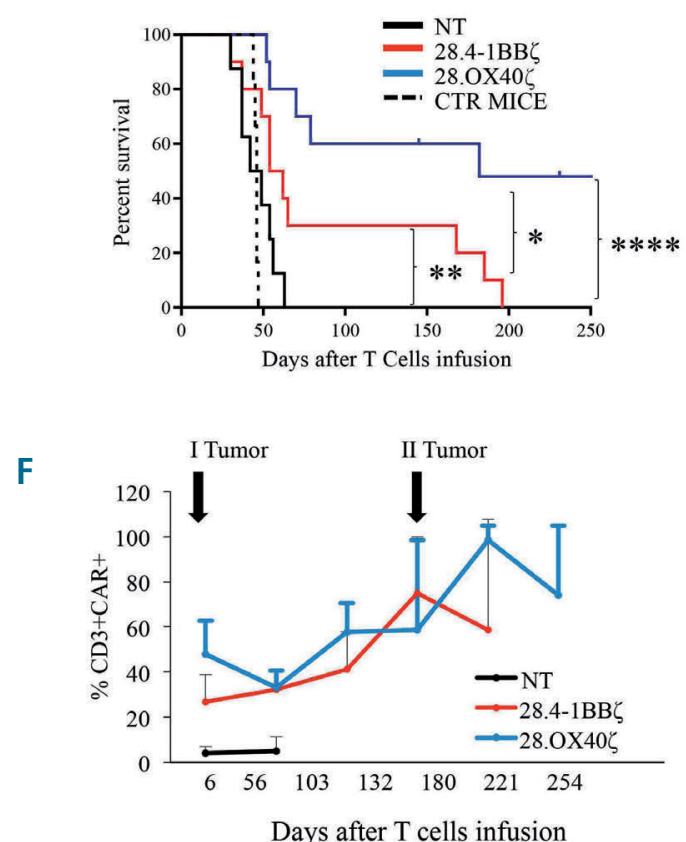

Figure 7. Re-challenge of the nonHodgkin lymphoma mouse model to evaluate long-term anti-lymphoma activity of CAR.CD30 T cells in generating an efficient immunological memory. (A) The schema shows the in vivo xenograft immunodeficient re-challenge mouse model, in which non-Hodgkin lymphoma Karpas-299-eGFP-FFLuc cells were systemically infused into NSG mice, at day -3 and day +140 . Effector cells were infused intravenously only once, at the time of tumor establishment (day 0) assessed by IVIS imaging. Blood was collected periodically from the mice. (B) IVIS imaging of tumor growth from day 0 to day +240 (end of experiment). At day +140 , surviving mice treated with CAR.CD30 T cells (2 mice treated with $28-41 B B \zeta$ and 4 mice with $28.0 \times 40 \xi$ T cells) received the second intravenous infusion of tumor. As a control, six mice were given only Karpas299-eGFP-FFLuc cells (CTR Mice). Days from the tumor re-challenge are shown in blue. (C) Bioluminescence of each single xenograft mouse treated with NT (black lines; 8 mice); $28.4-1 B B$ ' $\zeta$ T cells (red lines; 10 mice); $28.0 \times 40 \zeta$ T cells (blue line; 10 mice). Bioluminescence in the control cohort of the tumor re-challenge (CTR Mice) is shown by black dotted lines. Tumor infusions are represented by black arrows. (D) KaplanMeier survival curve analysis of tumorbearing mice treated with non-transduced (NT, black line), 28.4-1BB' (red line), 28.0X40 (blue line). Overall survival of control mice is shown by a dotted black line. $* P<0.05 ; * * P<0.001$ $* * * P<0.0001 ; \quad * * * * P<0.00001$. (E) Three-dimensional area graph showing the percentage of circulating human $\mathrm{CD}^{+} \mathrm{T}$ cells during long-term in vivo experiments of mice treated with NT (black area), 28.4-1BB' T cells (red area) and $28.0 \times 40$ ' $T$ cells (blue area). Tumor infusions are represented by black arrows. (F) Average percentages of circulating human $\mathrm{CD}^{+} / \mathrm{CAR}^{+} \mathrm{T}$ cells in mice treated with NT (black line), 28.4-1BBל $T$ cells (red line) and 28.0x40 $\zeta$ T cells (blue line). Black arrows represent tumor infusions.
$E$

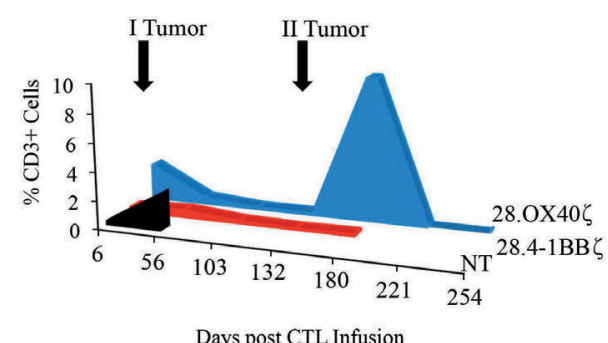

Days post CTL Infusion 
of exhaustion and limited in vivo persistence. Moreover, in the case of CAR.CD30, the low CD30 expression on CD3 ${ }^{+}$ $\mathrm{T}$ cells could also cause chronic antigen stimulation and the occurrence of cellular fratricide. ${ }^{31}$

Our experimental data indicate that the inclusion of an AC10-derived scFv in the CAR construct, independently of the co-stimulatory domains, was not associated with exhaustion, even after multiple $\mathrm{CD} 30^{+}$lymphoma-cell stimulations. Furthermore, we did not observe fratricidal activity among CAR.CD30 T-cell populations. With respect to co-stimulatory domains, we comparatively evaluated two III-CAR.CD30, incorporating either CD28.OX40 or CD28.4-1BB. The clinical impact of combining co-stimulatory domains has not yet been clearly established, and it may be construct- and diseasespecific. ${ }^{32,33}$ However, in the setting of repetitive antigen engagement, driving T-cell maturation to terminally differentiated cells associated with loss of CCR7, the combined CD285-OX40 signaling CAR rescued CCR7- $T$ cells from apoptosis resulting, in turn, in more efficient antitumor efficacy ${ }^{34}$ For early clinical development, trial designs comparing two CAR T cells simultaneously administered to the same patient have provided invaluable evidence of the pharmacokinetic effect of co-stimulatory domains. ${ }^{35-37}$ Ultimately, experimental evidence ${ }^{30,39}$ suggests that the positioning of co-stimulatory domains within the endodomain of a CAR can influence CAR T-cell activity, and no algorithm, up to now, has been able to predict which co-stimulatory combination is optimal for a specific CAR construct, making the search for optimized activity strictly dependent on experimental conditions. We recently showed the advantage of using the CD28.4-1BB co-stimulatory domain to optimize CAR T-cell therapy targeting GD2 ${ }^{+}$neuroblastoma. ${ }^{40}$ In the current study, however, we observed an in vivo superiority of the CAR.CD30 construct incorporating the CD28.OX40 co-stimulatory domains, in terms of both anti-lymphoma activity and CAR T-cell persistence. We also confirmed the in vitro data in an in vivo model, showing greater stability of the CAR.CD30.CD28.OX40 T-cell population, both in terms of $\mathrm{CAR}^{+}$cell percentage and CAR expression (MFI), even after repeated/prolonged exposures to tumor. CAR.CD30.CD28.OX40 T-cell activation profile correlates with efficient tumor control, stable expression of CAR molecule on the cell membrane and high production of IFN- $\gamma$, TNF- $\alpha$ and IL2 cytokines (Th1 profile). Evaluation of the cytokine activation profile is especially relevant in the context of lymphoma. Indeed, HL malignant cells express high levels of PDL1 and produce the immunosuppressive IL10, TGF $\beta$, galectin 1 and prostaglandin E2 molecules, which inhibit T-cell effector functions and induce apoptosis of activated Th1 and CD8 $8^{+} \mathrm{T}$ cells. ${ }^{41,42}$ We demonstrated that CAR.CD30.CD28.OX40 T cells and, in particular, the $\mathrm{CD}^{+}$fraction, exert significant and prolonged anti-lymphoma activity even in this strongly immune-modulating environment.

Importantly, we confirmed that the manufacturing process based on IL7/IL15 is crucial for optimizing CAR T-cell activity also in the lymphoma setting. In particular, we proved, both in vitro and in vivo, that CAR.CD30 T cells (IL7/IL15) systematically exposed to CD30+ lymphoma cells were significantly enriched in CM and EM subpopulations, in both $\mathrm{CD}^{+}$and $\mathrm{CD} 8^{+} \mathrm{T}$-cell subsets. Moreover, in a NHL xenograft mouse model, in which we mimic lymphoma relapse through tumor re-challenge, CAR.CD30.CD28.OX40 T cells were able to re-expand significantly and exert tumor control. We also showed that the number of CAR.CD30.CD28.OX40 T cells declined in peripheral blood upon lymphoma eradication. Thorough characterization of mouse tissues after longterm in vivo experiments $($ day +240$)$ revealed the presence of CAR.CD30.CD28.OX40 T cells in several organs, including bone marrow, lymph nodes, kidney, liver, spleen and thyroid.

The inclusion of the inducible "safety switch" iCasp9"3 is crucial to render the therapeutic approach safer, controlling potential unwanted side effects in the context of CAR T cells. We showed both in vitro and in vivo that AP1903 is able to significantly reduce iCasp9.CAR.CD30 cells. However, the persistence, albeit at very low levels, of genetically modified $\mathrm{T}$ cells with a low expression of CAR.CD30 after AP1903 treatment cannot be excluded.

Overall, the significant in vivo reactivity, the high poten$\mathrm{cy}$, the negligible toxicity in animals and the long persistence of CAR.CD30.CD28.OX40 T cells contribute to the value of this CAR design, which will be tested in a clinical trial for patients with relapsed/refractory HL and anaplastic large-cell lymphoma.

\section{Disclosures}

No conflicts of interest to disclose. A patent application has been made (n. 102018000003464).

\section{Contributions}

$M G, C Q, B D A$ and $F L$ designed experimental studies, supervised the conduction of the project, analyzed the data and wrote the manuscript. $M G, D O, S D C, M S, S C, I B, Z A, A C$, $B C, K B, I C, C D S, M P, E G, M S, S M, R C$ and $R D V$ performed the in vitro experiments. CDS and MP performed immunohistochemistry assays. $M G, I B, B D A$ and $C Q$ performed the in vivo experiments. DO, MG and BDA cloned the retroviral vector. $M G, E G, M S$ and $M S$ performed FACS analysis. $A R, F D B, P M, L V, K G, R D V, L M$ and $F L$ provided patients' samples, medical advice and expertise in pediatric lymphoma. SB, ACi and MT analyzed data. All authors read and approved the final version of the manuscript.

\section{Acknowledgments}

We are grateful to Bellicum Pharmaceuticals for kindly providing the AP1903 dimerizing drug.

\section{Funding}

The experimental work was supported by grants awarded by Ricerca Finalizzata GR-2016-02364546 (to BDA), Associazione Italiana Ricerca per la Ricerca sul Cancro (AIRC)Special Project 5×1000 n. 9962 (to FL), AIRC IG 2018 id. 21724 (to FL), Ricerca Finalizzata GR-2013-02359212 (to CQ), Ricerca Corrente (to CQ and BDA). Progetto Ministeriale CAR-T (to FL), and Associazione "Raffaele Passarelli" Onlus (to $B D A$ ). 


\section{References}

1. Sadelain M. Chimeric antigen receptors: driving immunology towards synthetic biology. Curr Opin Immunol. 2016;41:68-76.

2. Schuster SJ, Svoboda J, Chong EA, et al. Chimeric antigen receptor $T$ cells in refractory B-cell lymphomas. N Engl J Med. 2017;377(26):2545-2554

3. Locke FL, Ghobadi A, Jacobson CA, et al. Long-term safety and activity of axicabtagene ciloleucel in refractory large B-cell lymphoma (ZUMA-1): a single-arm, multicentre, phase 1-2 trial. Lancet Oncol. 2019;20(1):31-42

4. Rezvani AR, Storer B, Maris M, et al. Nonmyeloablative allogeneic hematopoietic cell transplantation in relapsed, refractory, and transformed indolent non-Hodgkin's lymphoma. J Clin Oncol. 2008;26(2):211217.

5. von Tresckow B, Moskowitz CH. Treatment of relapsed and refractory Hodgkin lymphoma. Semin Hematol. 2016:53(3):180-185.

6. Steidl C, Gascoyne RD. The molecular pathogenesis of primary mediastinal large Bcell lymphoma. Blood. 2011;118(10):26592669.

7. Sabattini E, Pizzi M, Tabanelli V, et al. CD30 expression in peripheral T-cell lymphomas. Haematologica. 2013;98(8):e81-82.

8. Bossard C, Dobay MP, Parrens M, et al. Immunohistochemistry as a valuable tool to assess CD30 expression in peripheral T-cell lymphomas: high correlation with mRNA levels. Blood. 2014;124(19):2983-2986.

9. Berger GK, Gee K, Votruba C, McBride A, Anwer F. Potential application and prevalence of the CD30 (Ki-1) antigen among solid tumors: a focus review of the literature. Crit Rev Oncol Hematol. 2017;113:8-17.

10. Pallesen G, Hamilton-Dutoit SJ. Ki-1 (CD30) antigen is regularly expressed by tumor cells of embryonal carcinoma. Am J Pathol. 1988;133(3):446-450

11. Hittmair A, Rogatsch H, Hobisch A, Mikuz G, Feichtinger H. CD30 expression in seminoma. Hum Pathol. 1996;27(11):1166-1171.

12. de Bruin PC, Gruss HJ, van der Valk P, Willemze R, Meijer CJ. CD30 expression in normal and neoplastic lymphoid tissue: biological aspects and clinical implications. Leukemia. 1995;9(10):1620-1627.

13. Agrawal B, Reddish M, Longenecker BM. CD30 expression on human CD8+ T cells isolated from peripheral blood lymphocytes of normal donors. J Immunol. 1996:157(8):3229-3234.

14. Bonthapally V, Wu E, Macalalad A, et al. Brentuximab vedotin in relapsed/refractory Hodgkin lymphoma post-autologous transplant: meta-analysis versus historical data. Curr Med Res Opin. 2015;31(5):993-1001.

15. Chen R, Gopal AK, Smith SE, et al. Five-year survival and durability results of brentuximab vedotin in patients with relapsed or refractory Hodgkin lymphoma. Blood. 2016;128(12):1562-1566.

16. Pro B, Advani R, Brice P, et al. Five-year results of brentuximab vedotin in patients with relapsed or refractory systemic anaplastic large cell lymphoma. Blood. 2017;130(25):2709-2717.

17. Moskowitz CH, Nademanee A, Masszi T, et al. Brentuximab vedotin as consolidation therapy after autologous stem-cell transplantation in patients with Hodgkin's lymphoma at risk of relapse or progression (AETHERA): a randomised, double-blind, placebo-controlled, phase 3 trial. Lancet. 2015:385(9980):1853-1862.

18. Thurber GM, Schmidt MM, Wittrup KD Antibody tumor penetration: transport opposed by systemic and antigen-mediated clearance. Adv Drug Deliv Rev. 2008;60(12):1421-1434.

19. Savoldo B, Rooney CM, Di Stasi A, et al. Epstein Barr virus specific cytotoxic T lymphocytes expressing the anti-CD30zeta artificial chimeric T-cell receptor for immunotherapy of Hodgkin disease. Blood. 2007;110(7):2620-2630.

20. Di Stasi A, De Angelis B, Rooney CM, et al. $\mathrm{T}$ lymphocytes coexpressing CCR4 and a chimeric antigen receptor targeting CD30 have improved homing and antitumor activity in a Hodgkin tumor model. Blood. 2009;113(25):6392-6402.

21. Wang CM, Wu ZQ, Wang Y, et al Autologous $\mathrm{T}$ cells expressing CD30 chimeric antigen receptors for relapsed or refractory Hodgkin lymphoma: an openlabel phase I trial. Clin Cancer Res. 2017;23(5):1156-1166.

22. Ramos CA, Ballard B, Zhang $\mathrm{H}$, et al Clinical and immunological responses after CD30-specific chimeric antigen receptorredirected lymphocytes. J Clin Invest. 2017;127(9):3462-3471.

23. Louis CU, Savoldo B, Dotti G, et al. Antitumor activity and long-term fate of chimeric antigen receptor-positive $T$ cells in patients with neuroblastoma. Blood. 2011:118(23):6050-6056.

24. Heczey A, Louis CU, Savoldo B, et al. CAR $\mathrm{T}$ cells administered in combination with lymphodepletion and PD-1 inhibition to patients with neuroblastoma. Mol Ther 2017;25(9):2214-2224.

25. Wahl AF, Klussman K, Thompson JD, et al The anti-CD30 monoclonal antibody SGN30 promotes growth arrest and DNA fragmentation in vitro and affects antitumo activity in models of Hodgkin's disease. Cancer Res. 2002;62(13):3736-3742

26. Quintarelli C, Orlando D, Boffa I, et al. Choice of costimulatory domains and of cytokines determines CAR T-cell activity in neuroblastoma. Oncoimmunology. 2018;7 (6):e1433518.

27. Di Stasi A, De Angelis B, Savoldo B. Gene therapy to improve migration of $\mathrm{T}$ cells to the tumor site. Methods Mol Biol. 2010;651:103-118.

28. Zheng Z, Chinnasamy N, Morgan RA. Protein L: a novel reagent for the detection of chimeric antigen receptor (CAR) expression by flow cytometry. J Transl Med. 2012;10:29

29. Zhu Y, Tan Y, Ou R, et al. Anti-CD19 chimeric antigen receptor-modified $T$ cells for B-cell malignancies: a systematic review of efficacy and safety in clinical trials. Eur Haematol. 2016;96(4):389-396.

30. Turtle CJ, Hanafi LA, Berger C, et al. Immunotherapy of non-Hodgkin's lymphoma with a defined ratio of CD8+ and CD4+ CD19-specific chimeric antigen receptor-modified T cells. Sci Transl Med. 2016;8(355):355ra116.

31. Hombach AA, Rappl G, Abken H. Blocking CD30 on T cells by a dual specific CAR for CD30 and colon cancer antigens improves the CAR $T$ cell response against CD30(-) tumors. Mol Ther. 2019;27(10):1825-1835.

32. Weinkove R, George P, Dasyam N, McLellan $\mathrm{AD}$. Selecting costimulatory domains for chimeric antigen receptors: functional and clinical considerations. Clin Transl Immunol. 2019;8(5):e1049.

33. Hombach AA, Rappl G, Abken H. Arming cytokine-induced killer cells with chimeric antigen receptors: CD28 outperforms combined CD28-OX40 "super-stimulation". Mol Ther. 2013;21(12):2268-2277.

34. Hombach AA, Chmielewski M, Rappl G, Abken $\mathrm{H}$. Adoptive immunotherapy with redirected $\mathrm{T}$ cells produces CCR7- cells that are trapped in the periphery and benefit from combined CD28-OX40 costimulation. Hum Gene Ther. 2013;24(3):259-269.

35. Cheng Z, Wei R, Ma Q, et al. In vivo expansion and antitumor activity of coinfused CD28- and 4-1BB-engineered CAR-T cells in patients with B cell leukemia. Mol Ther 2018;26(4):976-985

36. Savoldo B, Ramos CA, Liu E, et al. CD28 costimulation improves expansion and persistence of chimeric antigen receptor-modified T cells in lymphoma patients. J Clin Invest. 2011;121(5):1822-1826.

37. Ramos CA, Rouce R, Robertson CS, et al. In vivo fate and activity of second- versus third-generation CD19-specific CAR-T cells in B cell non-Hodgkin's lymphomas. Mol Ther. 2018:26(12):2727-2737.

38. Pule MA, Straathof KC, Dotti G, Heslop HE Rooney CM, Brenner MK. A chimeric T cell antigen receptor that augments cytokine release and supports clonal expansion of primary human $\mathrm{T}$ cells. Mol Ther 2005;12(5):933-941.

39. Hombach AA, Heiders J, Foppe M, Chmielewski M, Abken H. OX40 costimulation by a chimeric antigen receptor abrogates CD28 and IL-2 induced IL-10 secretion by redirected $\mathrm{CD} 4(+) \mathrm{T}$ cells. Oncoimmunology. 2012;1(4):458-466.

40. Orlando D, Miele E, De Angelis B, et al. Adoptive immunotherapy using PRAMEspecific $\mathrm{T}$ cells in medulloblastoma. Cancer Res. 2018;78(12):3337-3349.

41. Wein F, Kuppers R. The role of T cells in the microenvironment of Hodgkin lymphoma. JJ Leukoc Biol. 2016;99(1):45-50.

42. Wein F, Weniger MA, Hoing B, et al Complex immune evasion strategies in classical Hodgkin lymphoma. Cancer Immuno Res. 2017;5(12):1122-1132.

43. Gargett T, Brown MP. The inducible caspase- 9 suicide gene system as a "safety switch" to limit on-target, off-tumor toxicities of chimeric antigen receptor $\mathrm{T}$ cells. Front Pharmacol. 2014;5:235. 